\title{
Determination of free chlorine based on ion chromatography-application of glycine as a selective scavenger
}

\author{
Mohammad Sajjad Abdighahroudi ${ }^{1,2}($ D $) \cdot$ Torsten C. Schmidt ${ }^{1,3,4}(\mathbb{C}) \cdot$ Holger V. Lutze ${ }^{1,2,3,4} \mathbb{C}$
}

Received: 3 July 2020 / Revised: 4 August 2020 / Accepted: 13 August 2020 / Published online: 18 September 2020

(C) The Author(s) 2020

\begin{abstract}
Free available chlorine (FAC) is the most widely used chemical for disinfection and in secondary disinfection; a minimum chlorine residual must be present in the distribution system. FAC can also be formed as an impurity in $\mathrm{ClO}_{2}$ production as well as a secondary oxidant in the $\mathrm{ClO}_{2}$ application, which has to be monitored. In this study, a new method is developed based on the reaction of FAC with glycine in which the amine group selectively scavenges FAC and the $N$-chloroglycine formed can be measured by ion chromatography with conductivity detector (IC-CD). Utilizing IC for $N$-chloroglycine measurement allows this method to be incorporated into routine monitoring of drinking water anions. For improving the sensitivity, IC was coupled with post-column reaction and UV detection (IC-PCR-UV), which was based on iodide oxidation by $N$-chloroglycine resulting in triiodide. The method performance was quantified by comparison of the results with the $N, N$-diethyl- $p$-phenylenediamine (DPD) method due to the unavailability of an $N$-chloroglycine standard. The $N$-chloroglycine method showed limits of quantification (LOQ) of $24 \mu \mathrm{g} \mathrm{L}^{-1} \mathrm{Cl}_{2}$ and $13 \mu \mathrm{g} \mathrm{L}^{-1} \mathrm{Cl}_{2}$ for IC-CD and IC-PCR-UV, respectively. These values were lower than those of DPD achieved in this research and in ultrapure water. Measurement of FAC in the drinking water matrix showed comparable robustness and sensitivity with statistically equivalent concentration that translated to recoveries of $102 \%$ for IC-CD and $105 \%$ for IC-PCR-UV. Repeatability and reproducibility performance were enhanced in the order of DPD, IC-CD, and ICPCR-UV. Measurement of intrinsic FAC in the $\mathrm{ClO}_{2}$ application revealed that the $\mathrm{N}$-chloroglycine method performed considerably better in such a system where different oxidant species $\left(\mathrm{ClO}_{2}, \mathrm{FAC}\right.$, chlorite, etc.) were present.
\end{abstract}

Keywords Free available chlorine $($ FAC $) \cdot$ Ion chromatography $\cdot$ Chlorine dioxide $\cdot$ Secondary oxidant $\cdot$ Intrinsic FAC formation

Electronic supplementary material The online version of this article (https://doi.org/10.1007/s00216-020-02885-1) contains supplementary material, which is available to authorized users.

Holger V. Lutze

h.lutze@iwar.tu-darmstadt.de

1 Faculty of Chemistry, Instrumental Analytical Chemistry, University of Duisburg-Essen, Universitätsstraße 5, 45141 Essen, Germany

2 Department of Civil and Environmental Engineering, Institute IWAR, Chair of Environmental Analytics and Pollutants, Technical University of Darmstadt, Franziska-Braun-Straße 7, 64287 Darmstadt, Germany

3 IWW Water Centre, Moritzstraße 26, 45476 Mülheim an der Ruhr, Germany

4 Centre for Water and Environmental Research (ZWU), Universitätsstraße 5, 45141 Essen, Germany

\section{Introduction}

Chlorination is in use for disinfection of water since the end of the nineteenth century. Its usage became popular after 1920 and still is the most common form of water treatment worldwide [1]. Free available chlorine (FAC) refers to the amount of chlorine present in water as hypochlorous acid and hypochlorite ions [2]. Because FAC may form chlorinated by-products, chloramination (formation of inorganic monochloramine) as an alternative disinfectant in distribution systems has gained interest [3], which, however, may form nitrosamines [4]. Numerous methods have been developed to measure FAC and chloramine species. Most of the common methods to measure FAC such as iodometric and amperometric titration and reaction with $N, N$-diethyl-p-phenylenediamine (DPD) are prone to error, e.g., by buffering capacity, which may aggravate $\mathrm{pH}$ adjustment [5] or interferences of several other oxidants such as chloramines and chlorine dioxide $\left(\mathrm{ClO}_{2}\right)[5,6]$. 
FAC can also be formed during $\mathrm{ClO}_{2}$ generation [7] as impurity and has to be controlled in $\mathrm{ClO}_{2}$ applications. However, most conventional methods cannot selectively measure FAC in the presence of $\mathrm{ClO}_{2}$. For example, the DPD method requires two measurements in the presence and absence of scavenger for FAC. FAC can be calculated by subtracting the measurement result for the sample with FAC scavenger from the result for the sample without FAC scavenger. This results in an accumulative error that is especially pronounced in the case of low FAC concentrations in the presence of high $\mathrm{ClO}_{2}$ concentrations [8].

Moreover, intrinsic formation of $\mathrm{FAC}$ as $\mathrm{HOCl}$ in reactions of $\mathrm{ClO}_{2}$ with organic compounds has been proposed [9-11]. Recently, this secondary oxidant formation proved to occur in the reaction of $\mathrm{ClO}_{2}$ with phenol $[12,13]$. Determination of "intrinsic FAC yields" in $\mathrm{ClO}_{2}$ application is essential since it affects disinfection, pollutant degradation, as well as byproduct formation. Determination of intrinsic FAC yields, e.g., from reactions of $\mathrm{ClO}_{2}$, can only be done with a selective scavenger, since formed FAC may also be consumed, e.g., by organic matter.

Glycine is commonly used as the selective scavenger [6] as it reacts fast with FAC [14] and shows a very low reaction rate with $\mathrm{ClO}_{2}$ [15]. This provides a selective scavenging step in which the corresponding chloramine is formed. With glycine present in excess over chlorine, the yield of $N$-chloroglycine can be used to assess the FAC concentration. However, due to the lack of an easy and cheap method to measure $N$ chloroglycine, this scavenger was not used for FAC measurement so far.

Formation of $N$-chloroglycine as the product of the reaction between glycine and FAC is known and has been investigated thoroughly [16-18]. Despite the different species of glycine $(\mathrm{pKa} 1=2.35, \mathrm{pKa} 2=9.78)$ and $\mathrm{HOCl}\left(\mathrm{p} K_{\mathrm{a}}=7.4\right)[19]$ present in aqueous solution (cf. speciation of glycine and $\mathrm{HOCl}$ Fig. S1 in the Electronic Supplementary Material, ESM), the most relevant reaction according to Armesto et al. [16] is the one shown in Eq. 1.

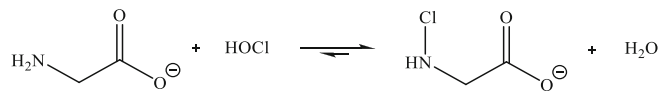

The reaction kinetics of Eq. 1 is reported to be between $10^{7}$ and $10^{8} \mathrm{M}^{-1} \mathrm{~s}^{-1}\left(k_{\mathrm{app}}=10^{5} \mathrm{M}^{-1} \mathrm{~s}^{-1}\right.$ at $\mathrm{pH}$ 7) [14], enabling very good scavenging of FAC. Due to the substitution of hydrogen by chlorine, the $\mathrm{p} K_{\mathrm{a}}$ values of the amino and carboxylic group are lowered. Thus, the anionic species of $N$ chloroglycine is the major species at $\mathrm{pH}>4$ and can be determined by ion chromatography (IC) (speciation of $\mathrm{N}$ chloroglycine cf. Fig. S2, see ESM).

This work aims to develop an alternative method to measure FAC by measurement of $N$-chloroglycine using IC. With the regulation of inorganic anions such as fluoride, nitrite and nitrate, chloride, and sulfate [20-22] and introduction of IC standard methods to quantify them [23, 24], anion-IC became one of the routine analytical methods in drinking water surveillance. Therefore, this method will not only facilitate the measurement of FAC in the presence of $\mathrm{ClO}_{2}$ but also be easily incorporated into routine monitoring of drinking water treatment processes. This will allow simultaneous measurement of FAC alongside anions in drinking water facilities with less susceptibility to interferences than conventional methods for FAC determination such as DPD method. The performance of the method will be investigated in FAC measurement in real water matrix, in the presence of $\mathrm{ClO}_{2}$, and intrinsic FAC formation. Since no standard of $N$-chloroglycine is commercially available, the performance of the method will be characterized in comparison with DPD as the standard method.

\section{Material and methods}

\section{Chemicals}

All chemicals were commercially available and used as received (purity is presented in parenthesis): Glycine (99\%), sodium chlorite $(80 \%)$, potassium chlorate $(99.0 \%)$ from Sigma-Aldrich ammonium molybdate tetrahydrate (99\%), potassium iodide (99\%), and $N, N$-diethyl-p-phenylenediamine sulfate (97\%) from Alfa Aesar sulfuric acid analytical (95\%) from Fisher Scientific, sodium nitrate (99.5\%), sodium carbonate $(99.5 \%)$, and sodium hydrogen carbonate (99\%) from Carl Roth and Riedel de Haen, respectively. $\mathrm{Na}_{2}$ EDTAx $2 \mathrm{H}_{2} \mathrm{O}$ (98\%), $\mathrm{Na}_{2} \mathrm{HPO}_{4} \times 2 \mathrm{H}_{2} \mathrm{O}$ (99.5\%), $\mathrm{KH}_{2} \mathrm{PO}_{4}$ (99.5\%) from AppliChem. Sodium fluoride (99.5\%) from Merck, sodium chloride $(99.5 \%)$ from Bernd Kraft, sodium bromide (99\%) from Fluka, and sodium sulfate anhydrous $(99.1 \%)$ from VWR chemicals.

Sodium hypochlorite $\left(2 \mathrm{mmol} \mathrm{L}^{-1}\right)$ was freshly produced from an 11-15\% stock solution (Alfa Aesar) (daily basis). The concentration of $\mathrm{OCl}^{-}$was verified by measuring UV absorption (optical path length $1 \mathrm{~cm}, \mathrm{pH}>10, \varepsilon_{\mathrm{OCl}}{ }^{-}$at $292 \mathrm{~nm}=$ $350 \mathrm{M}^{-1} \mathrm{~cm}^{-1}$ [25]). To take into account that besides $\mathrm{HOCl}$, also $\mathrm{Cl}_{2}$ and $\mathrm{OCl}^{-}$may be present in solution, $\mathrm{HOCl}$ is referred to as $\mathrm{FAC}$, and its concentration is reported as $\mathrm{Cl}_{2} . \mathrm{N}$ Chloroglycine was produced by mixing the $\mathrm{FAC}$ solution with glycine. To avoid the formation of $N, N$-dichloroglycine, FAC to glycine ratio was 0.1 [18]. The concentration of $N$ chloroglycine in the stock solution was confirmed by UV 
measurements (optical path length $10 \mathrm{~cm}, \mathrm{pH} \geq 4, \varepsilon_{N-}$ chloroglycine at $254 \mathrm{~nm}=375 \mathrm{M}^{-1} \mathrm{~cm}^{-1}$ [26]).

\section{Instruments}

Ultra-pure water was produced using PURELAB ultra from ELGA. For UV-Vis measurement, a Shimadzu UV-1800 spectrometer was used. Ion chromatography was performed using a Metrohm 881 Compact IC pro, including an 814 compact autosampler, 800 Dosino, and a MagIC Net 3.1 software for data acquisition and processing. The IC system was coupled with a post-column reaction (HT reactor Metrohm) using Spetec Perimax peristaltic pump for reagent delivery and a 944 UV detector. For separation, Metrosep A Supp 4, $5,7,10$, and 16 (all with dimensions of $250 \mathrm{~mm} \times 4.0 \mathrm{~mm}$ ) columns were tested, and eventually, Metrosep A Supp 7 was used.

\section{Ion chromatography method}

The injection volume was set to $300 \mu \mathrm{L}$. Used eluent was a $1.6 \mathrm{mmol} \mathrm{L}^{-1}$ sodium carbonate solution delivered with a flow rate of $0.8 \mathrm{~mL} \mathrm{~min}^{-1}$. To increase the sensitivity of the $N$ chloroglycine method, an iodometric post-column reaction combined with UV detection (PCR-UV) was used according to DIN EN ISO 11206 [27]. Organic chloramines such as $N$ chloroglycine react with iodide to form triiodide (Eq. 2) [26]. The triiodide formed in this reaction can be measured by UV absorption at $352 \mathrm{~nm}$ with high sensitivity ( $\varepsilon=$ 26,000 $\mathrm{M}^{-1} \mathrm{~cm}^{-1}$ [26]).

$\mathrm{RNHCl}+3 \mathrm{I}^{-}+\mathrm{H}^{+} \rightarrow \mathrm{RNH}_{2}+\mathrm{Cl}^{-}+\mathrm{I}_{3}^{-}$

PCR included potassium iodide (KI) and a catalyst, delivered by a peristaltic pump with a combined flow rate of $0.2 \mathrm{~mL} \mathrm{~min}^{-1}$. The concentration of the KI solution was $270 \mathrm{mmol} \mathrm{L}^{-1}$. The catalyst solution was composed of ammonium molybdate tetrahydrate $\left(50 \mu \mathrm{mol} \mathrm{L}^{-1}\right)$ and sulfuric acid (100 mmol L ${ }^{-1}$ ). A scheme of the setup is shown in Fig. S3 (see ESM). Scavenging of FAC by glycine was performed by adding $10 \mathrm{~mL}$ of sample to $1 \mathrm{~mL}$ of a $5 \mathrm{mmol} \mathrm{L}^{-1}$ glycine solution (i.e., more than 5 times excess of glycine over the highest expected FAC concentration $\left(70 \mu \mathrm{mol} \mathrm{L}{ }^{-1} \mathrm{Cl}_{2}\right)$ ). Then the sample was analyzed with IC using a conductivity detector (IC-CD) and post-column reaction with a UV detector (IC-PCR-UV). Using PCR-UV also allows measuring monochloramine in case the cation suppressor is by-passed (see Text $\mathrm{S} 1$ in ESM).

\section{DPD method}

The applied DPD method was based on DIN EN ISO 7393-2 [28]. In brief, $0.5 \mathrm{~mL}$ of buffer (phosphate, $\approx 500 \mathrm{mmol} \mathrm{L}^{-1}$ ) and $0.5 \mathrm{~mL}$ of DPD solution $\left(\approx 4.2 \mathrm{mmol} \mathrm{L}^{-1}\right)$ were added to a beaker; afterward, $10 \mathrm{~mL}$ of the sample was added. After a reaction time of $1 \mathrm{~min}$, the absorbance at $510 \mathrm{~nm}$ was measured with a UV-Vis spectrometer. The buffer solution was prepared by dissolving $30.1 \mathrm{~g} \mathrm{Na}_{2} \mathrm{HPO}_{4} \times 2 \mathrm{H}_{2} \mathrm{O}, 46.0 \mathrm{~g}$ $\mathrm{KH}_{2} \mathrm{PO}_{4}, 0.8 \mathrm{~g} \mathrm{Na}_{2}$ EDTAx $2 \mathrm{H}_{2} \mathrm{O}$ in a $1000-\mathrm{mL}$ volumetric flask and filled up with ultrapure water. For the preparation of DPD reagent solution $250 \mathrm{~mL}$ ultrapure water, $0.2 \mathrm{~g}$ $\mathrm{Na}_{2}$ EDTAx $2 \mathrm{H}_{2} \mathrm{O}$, and $2 \mathrm{~mL}$ concentrated sulfuric acid were added to a $1000-\mathrm{mL}$ volumetric flask. Then, $1.1 \mathrm{~g}$ water-free DPD was added to the same volumetric flask. After the dissolution of all reagents, it was filled up to the mark with ultrapure water.

\section{Measurement of FAC in the presence of $\mathrm{ClO}_{2}$}

To measure $\mathrm{FAC}$ in the presence of $\mathrm{ClO}_{2}$, samples were measured with the DPD method [6]. In short, samples with different ratios of $\mathrm{FAC}$ and $\mathrm{ClO}_{2}$ were divided into two fractions (A and B). Fraction A was measured with the DPD method. The reading of these samples (reading $A$ ) represents both $\mathrm{ClO}_{2}$ and FAC. Glycine was added to fraction B, which scavenges FAC. Afterward, fraction B was measured by the DPD method, which gives a signal for $\mathrm{ClO}_{2}$ (reading $\mathrm{B}$ ). Subtracting reading $\mathrm{B}$ from reading A equals FAC. A scheme of the procedure for the measurement of FAC in the presence of $\mathrm{ClO}_{2}$ is presented in Fig. S4 (see ESM). The glycine-containing samples (fraction B) were also measured with IC for the determination of $N$ chloroglycine.

To measure intrinsic FAC formed in $\mathrm{ClO}_{2}$ applications, samples containing $10 \mu \mathrm{mol} \mathrm{L}{ }^{-1}$ phenol were spiked with different $\mathrm{ClO}_{2}$ concentrations at $\mathrm{pH} 7$ at room temperature (sample A) and was treated as described above for fraction A. This reading represents both the remaining $\mathrm{ClO}_{2}$ and intrinsic FAC formed in the sample (note that the reaction of $\mathrm{ClO}_{2}$ with phenol yields FAC (see above)). Parallel to these samples, another set of samples in the presence of glycine for scavenging FAC was spiked with $\mathrm{ClO}_{2}$ (sample $\mathrm{B}$ ). In both samples, DPD was added $1 \mathrm{~h}$ after the $\mathrm{ClO}_{2}$ dosage. Subtraction of the reading of samples B from samples A equals intrinsic FAC. A scheme of the procedure for the measurement of intrinsic FAC is presented in Fig. S5 (see ESM). Furthermore, sample B was measured with IC directly without further treatment for $N$-chloroglycine determination.

\section{Method validation}

Due to the lack of $N$-chloroglycine standards, the FAC samples were always measured with both the $N$-chloroglycine and DPD method, and the results were compared for method validation purposes. The limit of quantification was calculated by a signal to noise ratio of 10 using maximum noise variation close to the corresponding peak. Method standard deviation 
was calculated by dividing the residual standard deviation of the calibration curve to its slope. Linearity was compared with DPD in the $30-5000 \mu \mathrm{g} \mathrm{L}^{-1} \mathrm{Cl}_{2}$ range suggested in the DIN EN ISO 73 93-2 method for colorimetric determination of free chlorine using DPD [28]. Recoveries of IC-CD and IC-PCRUV were calculated relative to DPD, and repeatability and reproducibility are calculated as the standard deviation of triplicate intraday and interday measurement, respectively. $T$ test was used to compare the resulting values from DPD and $N$ chloroglycine methods based on Miller et al. [29]. In that, a pooled estimate of standard deviations is calculated based on Eq. 3 and used to calculate $t$ value based on Eq. 4 .

$s=\frac{\left(n_{1}-1\right) s_{1}^{2}+\left(n_{2}-1\right) s_{2}^{2}}{\left(n_{1}+n_{2}-2\right)}$

$t=\frac{\bar{x}_{1}-\bar{x}_{2}}{s\left(\frac{1}{n_{1}}+\frac{1}{n_{2}}\right)}$

where $s_{\mathrm{i}}$ is the standard deviation of the measurements using either IC-CD, IC-PCR-UV, or DPD method, and $s$ is the pooled estimate of the standard deviation. $n_{\mathrm{i}}$ is the number of corresponding measurements for each method and $\bar{x}_{i}$ is the average of the resulting values.

\section{Results and discussion}

\section{Method development and validation}

In a preliminary set of experiments, different columns, including A Supp 4, 5, 7, 10, and 16, were tested regarding retention behavior. However, no signal for $N$-chloroglycine was detected using A Supp 10 and 16, while in separation using A Supp 4,5 , and 7 columns, a peak was observed. It was noted that the first group uses polystyrene-divinylbenzene copolymer with quaternary ammonium as solid-phase material, while polyvinyl alcohol with quaternary ammonium is the stationary phase for the second group, according to the manufacturer. This can indicate that $\mathrm{N}$-chloroglycine might react with the different solid-phase material as a chloramine. Moreover, by using the standard carbonate eluents of A Supp 4, 5, and 7 columns, chlorite and $\mathrm{N}$-chloroglycine peaks coeluted to some extent. By utilizing A Supp 7 and a weak eluent with a concentration of $1.6 \mathrm{mmol} \mathrm{L}{ }^{-1}$ sodium carbonate with a flow rate of $0.8 \mathrm{~mL} \mathrm{~min}{ }^{-1}$, it was possible to separate these two compounds (Fig. 1a) and also common anions in the drinking water sample (Fig. 1b). It is worth mentioning that for samples that do not contain chlorite, standard or stronger eluents with higher flow rates can be utilized. It is also possible to use A
Supp 4 or 5, which have lower column capacity. Employing these recommendations will reduce the retention of compounds such as sulfate and, thus, decrease the overall runtime. Different solid-phase material behavior, as well as different suppression techniques, can also be subject to future research.

To investigate the performance of the $N$-chloroglycine method, several series of samples were measured with DPD and IC. The respective method performance parameters for the $N$-chloroglycine method using both IC-CD and IC-PCR$\mathrm{UV}$, as well as common anions in drinking water, are shown in Table 1 . The employment of the $\mathrm{N}$-chloroglycine method is most interesting in the case of $\mathrm{ClO}_{2}$ applications (see 3.2) since it allows to measure all main by-products (chlorite, chloride, chlorate, and intrinsic FAC) simultaneously; therefore, the method performance for chlorite and chlorate is also presented in Table 1. Gordon et al. [8] reported LOQ of colorimetric DPD method for FAC to be $10 \mu \mathrm{g} \mathrm{L}^{-1} \mathrm{Cl}_{2}$. This is slightly below the LOQ determined in our study as well as DIN EN ISO 7393-2 [28], which can be explained by differences in the experimental setup. Considering that the LODs and LOQs were determined in different laboratories and by different persons, the LOQ reported in literature agrees with the LOQ determined in the present study.

Moreover, measurement of FAC in a range close to the LOQ shows that the $95 \%$ confidence interval for IC-PCRUV is slightly smaller than for DPD (ESM Fig. S6).

Another important parameter is the linearity of the method. According to DIN EN ISO 7393-2 [28], the DPD method has a range from 30 to $5000 \mu \mathrm{g} \mathrm{L}^{-1} \mathrm{Cl}_{2}$ and, thus, both methods are compared in this range. As shown in Fig. S7 (see ESM), the calibration line for $N$-chloroglycine method has a higher correlation coefficient compared with the DPD method. Figure S8 (see ESM) represents the residuals of the DPD and $\mathrm{N}$-chloroglycine method calibration lines, and a trend can be seen in the DPD method, indicating a non-linear behavior. Previous results of Gordon et al. [30] using $\mathrm{KMnO}_{4}$ to oxidize DPD showed similar behavior. This is due to further oxidation of the Würster dye to form the colorless imine. The lower the ratio of DPD to chlorine, the higher the chance of the imine formation, which may limit the working range of the colorimetric DPD method. Gordon et al. [30] managed to overcome this problem by using 100 times higher concentration of DPD $\left(110 \mathrm{~g} \mathrm{~L}^{-1} \approx 0.451 \mathrm{~mol} \mathrm{~L}^{-1}\right)$ in the DPD method. This problem is not observed for the glycine method, which had a glycine concentration as low as $375 \mathrm{mg} \mathrm{L}^{-1}(\approx$ $0.005 \mathrm{~mol} \mathrm{~L}^{-1}$ ).

Method performance in tap water matrix was investigated by characterizing recovery, repeatability, and reproducibility. To that end, different concentrations of FAC were spiked to tap water at typical drinking water concentrations. Results of IC-CD and IC-PCR-UV detection are compared with those of the DPD method in Fig. 2. The slopes of both lines are close to one, indicating a good correlation between 
Fig. 1 IC chromatograms of $N$ chloroglycine method using eluent $1.6 \mathrm{mmol} \mathrm{L}^{-1}$ sodium carbonate, flowrate of $0.8 \mathrm{~mL} \mathrm{~min}^{-1}$, PCR [KI] = $270 \mathrm{mmol} \mathrm{L}^{-1}$, [ammonium molybdate tetrahydrate $]=$ $50 \mu \mathrm{mol} \mathrm{L}^{-1}$, [sulfuric acid] = $100 \mathrm{mmol} \mathrm{L}^{-1}$, KI was added separately, flowrate of PCR reagents $0.2 \mathrm{~mL} \mathrm{~min}^{-1}$, wavelength of UV detection $352 \mathrm{~nm}$, injection volume $300 \mu \mathrm{L}$, (a) an ultrapure water sample containing $200 \mu \mathrm{g} \mathrm{L}^{-1}$ FAC detected as $N$-chloroglycine, $200 \mu \mathrm{g} \mathrm{L}^{-1} \mathrm{ClO}_{2}$ detected as chlorite resulting from the alkaline decomposition of $\mathrm{ClO}_{2}$ in high $\mathrm{pH}$ of the eluent, and chloride and bromide as impurities of sodium hypochlorite solution (b) a tap water sample spiked with $800 \mu \mathrm{g} \mathrm{L}^{-1}$ FAC and measured with conductivity detector (upper part of the figure shows the total chromatogram, and the lower part represents an enlarged view of the baseline and smaller peaks). Note that chlorite and chlorate were not present in the drinking water sample and thus not detected
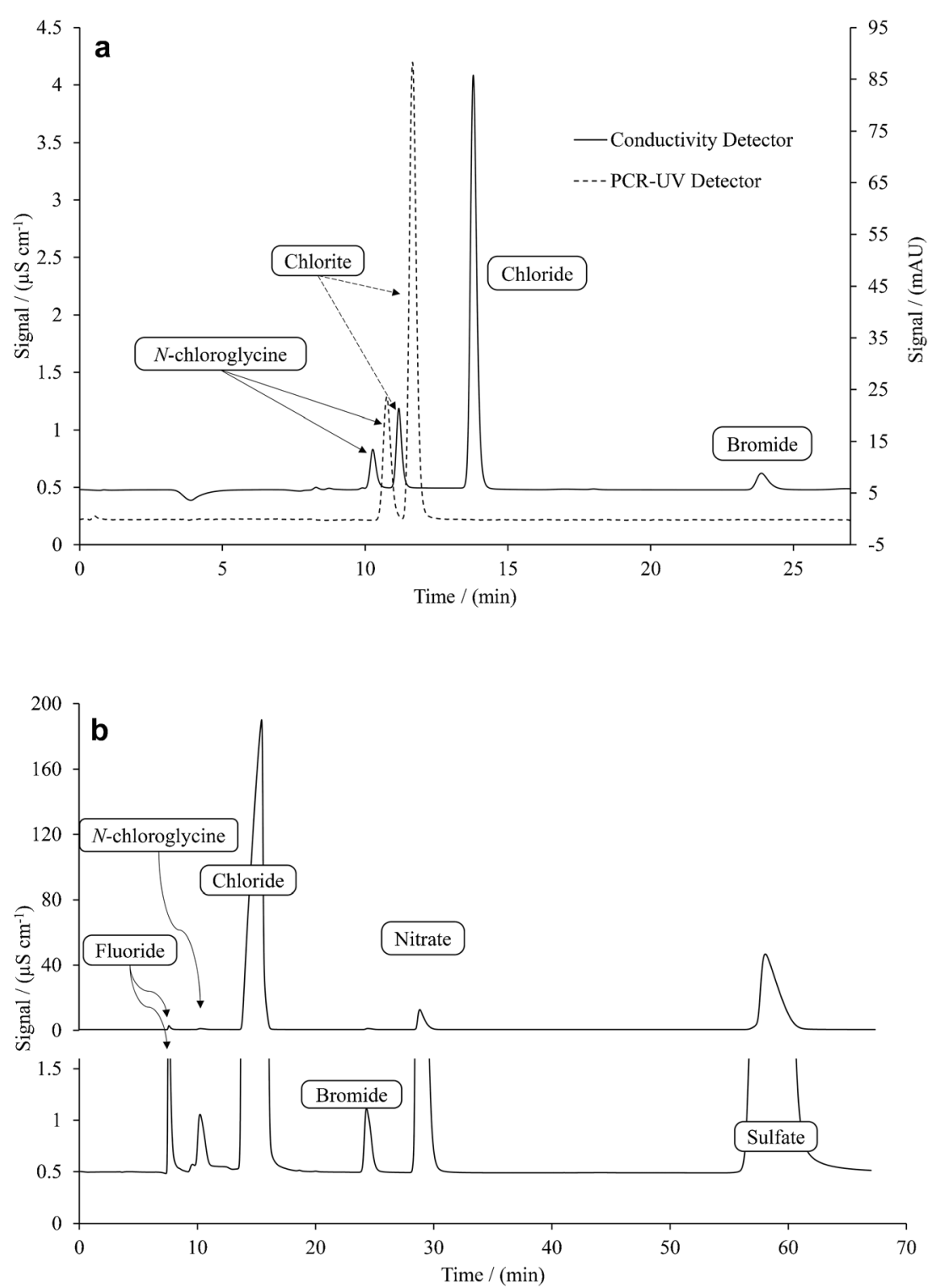

the measurement of IC methods with DPD. Moreover, the concentrations of the triplicate measurements with these methods were statistically equivalent $(\alpha=0.05)$. The average recoveries of IC-CD and IC-PCR-UV calculated relative to the DPD method were 102 and $105 \%$, respectively. Thus, the determined concentrations in the drinking water matrix are in very good agreement with the concentrations obtained in ultrapure water (Table 1). For other matrices, it is recommended to calculate the individual matrixdependent LOQ on the basis of the recovery rates in analogy to Mechelke et al. [31]. The relative standard deviation (RSD) of the samples measured during the same day (repeatability/intraday) with DPD (5.9\%), IC-CD (3.7\%), ICPCR-UV (3.2\%), indicates similar or better performance of IC methods (IC-PCR-UV and IC-CD). Reproducibility (interday) measurements performed within 3 weeks with freshly prepared eluents also showed statistically equivalent concentration $(\alpha=0.05)$ with similar relative standard deviations for IC-CD (2.4\%) and IC-PCR-UV (3.4\%) compared with DPD (3.9\%) (average). As mentioned above, it is possible to measure FAC alongside common anions in drinking water. Concentrations of anions present in the tap water used for the method validation study are presented in Table S1 (see ESM). Chromatograms of IC-CD and ICPCR-UV corresponding to one of the spiked tap water samples are shown in Fig. $1 \mathrm{~b}$.

From the results, it can be concluded that the $N$ chloroglycine method has comparable performance with the DPD method in the measurement of FAC in a water matrix that is common in drinking water. However, DPD oxidation can also happen in reaction with $\mathrm{ClO}_{2}$, ozone, $\mathrm{H}_{2} \mathrm{O}_{2}$, permanganate, bromine, iodine [32], disinfection by-products such as 
Table 1 Method performance parameters for measurement of FAC and drinking water anions using different methods $(\mathrm{FAC}=$ added $\mathrm{HOCl}$, expressed as $\mathrm{Cl}_{2}$ equivalents)

\begin{tabular}{|c|c|c|c|c|c|}
\hline Method & $\begin{array}{l}\text { Slope or sensitivity/ } \\
\left(\text { peak area } \times \mu g^{-1} \mathrm{~L}\right)\end{array}$ & $\begin{array}{l}\text { Intercept/ } \\
\text { (peak area) }\end{array}$ & $\begin{array}{l}R^{2} \\
\text { correlation } \\
\text { coefficient }\end{array}$ & $\begin{array}{l}\text { Method standard } \\
\text { deviation }^{\mathrm{a} /} \\
\left(\mu \mathrm{g} \mathrm{L}^{-1}\right)\end{array}$ & $\begin{array}{l}\mathrm{LOQ}^{\mathrm{b}} / \\
\left(\mu \mathrm{g} \mathrm{L}^{-1}\right)\end{array}$ \\
\hline $\begin{array}{l}\text { FAC by } \\
\text { IC-CD }\end{array}$ & $(3.8 \pm 0.1) \times 10^{-5}$ & $\begin{array}{l}-0.0009 \\
\quad \pm 0.0009\end{array}$ & 0.9949 & 2.6 & 24 \\
\hline $\begin{array}{l}\text { FAC by } \\
\text { IC-PCR-UV }\end{array}$ & $(3.39 \pm 0.07) \times 10^{-2}$ & $-0.08 \pm 0.04$ & 0.9989 & 1.2 & 13 \\
\hline FAC by DPD & $(2.18 \pm 0.09) \times 10^{-4}$ & $0.0095 \pm 0.0005$ & 0.9947 & 2.7 & 68 \\
\hline Fluoride & $(44.2 \pm 0.5) \times 10^{-4}$ & $-0.016 \pm 0.003$ & 0.9995 & 0.79 & 2.2 \\
\hline Chloride & $(15.6 \pm 0.2) \times 10^{-3}$ & $-0.06 \pm 0.01$ & 0.9992 & 1 & 4 \\
\hline Bromide & $(9.1 \pm 0.1) \times 10^{-4}$ & $\begin{array}{l}-0.0015 \\
\quad \pm 0.0006\end{array}$ & 0.9995 & 0.77 & 3.9 \\
\hline Nitrate & $(12.7 \pm 0.3) \times 10^{-4}$ & $0 \pm 0.001$ & 0.9987 & 1.3 & 5 \\
\hline Sulfate & $(24.8 \pm 0.6) \times 10^{-4}$ & $-0.007 \pm 0.003$ & 0.9993 & 0.90 & 12.6 \\
\hline $\begin{array}{l}\text { Chlorite by } \\
\text { IC-CD }\end{array}$ & $(12.9 \pm 0.5) \times 10^{-4}$ & $-0.03 \pm 0.01$ & 0.9955 & 8.3 & 28 \\
\hline $\begin{array}{l}\text { Chlorite by } \\
\text { IC-PCR-UV }\end{array}$ & $(19 \pm 0.4) \times 10^{-2}$ & $-2.9 \pm 0.9$ & 0.9983 & 4.9 & 19 \\
\hline Chlorate & $(6.81 \pm 0.2) \times 10^{-4}$ & $-0.002 \pm 0.005$ & 0.9938 & 10 & 40 \\
\hline
\end{tabular}

${ }^{\text {a }}$ Residual standard deviation/sensitivity (slope)

${ }^{\mathrm{b}} \mathrm{S} / N=10$

inorganic [33, 34], and organic chloramines [35], bromamines [36] and bromochloramines [37], chlorite and chlorate [38], and oxidized manganese species $\left(\mathrm{MnO}_{2}, \mathrm{MnO}_{4}{ }^{-}\right)$[6]. This exacerbates a reliable measurement of FAC using DPD, while in the new IC-based method, these interferences do not exist due to the measurement of $\mathrm{N}$-chloroglycine as the product of the reaction between FAC and glycine.

One point to discuss in $\mathrm{N}$-chloroglycine method is the presence of glycine as one of the free amino acids with the highest concentration in raw water [39]. However, the concentration of free amino acids in raw water is reported to be around $2.5 \mu \mathrm{g} \mathrm{L}^{-1}$ at highest with a maximum of $20 \%$ glycine content. Moreover, compared with FAC, glycine concentration is way lower, and in excess of FAC, $N, N$-dichloroglycine will form $[18,40,41]$. $N, N$ Dichloroglycine is subject to fast auto-decomposition $\left(t_{1 / 2}=13.0 \mathrm{~min}\right)$ [42]. All in all, it is implausible that background glycine concentration will cause any interferences due to low abundance and further degradation of $N, N$-dichloroglycine.
Fig. 2 FAC measured by $N$ chloroglycine method using IC$\mathrm{CD}$ and IC-PCR-UV compared with the DPD method. The tap water sample was spiked with different FAC concentrations. Error bars show the standard deviation of triplicate measurements. $(\mathrm{FAC}=$ added $\mathrm{HOCl}$, expressed as $\mathrm{Cl}_{2}$ equivalents)

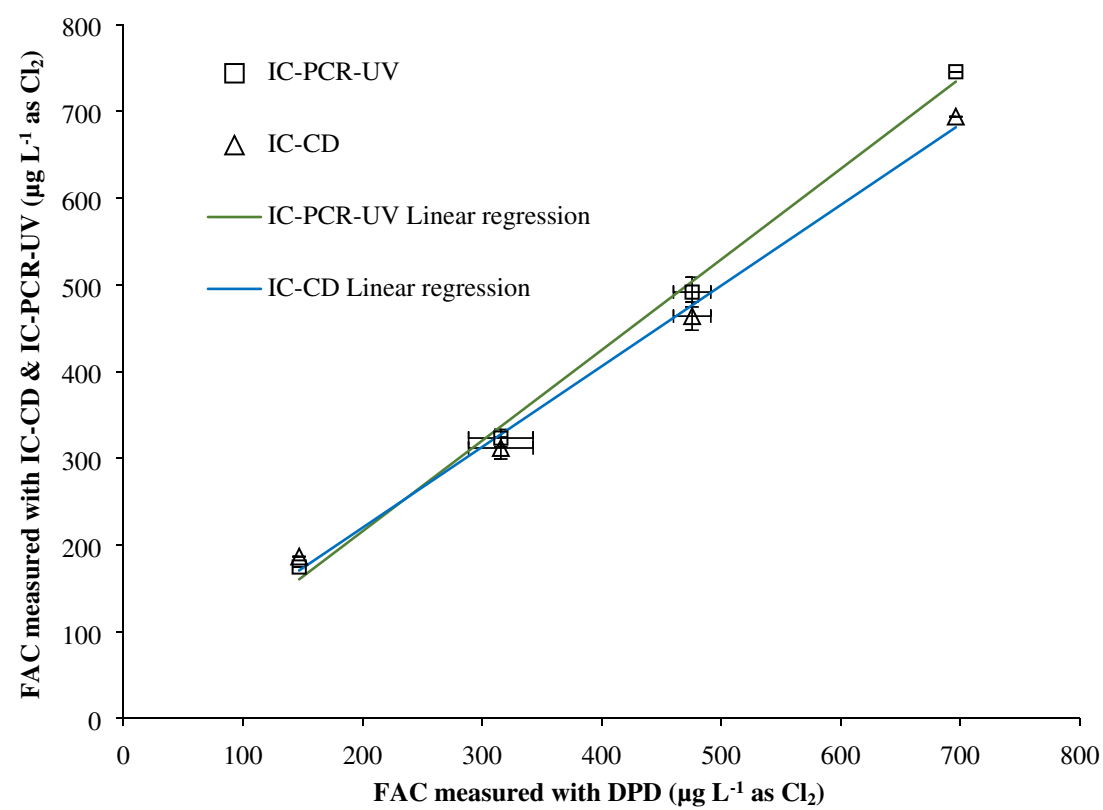




\section{Measurement of $\mathrm{FAC}$ in presence of $\mathrm{ClO}_{2}$}

The performance of the $\mathrm{N}$-chloroglycine method for measurement of FAC impurities in $\mathrm{ClO}_{2}$ production was compared with the DPD method for the measurement of FAC. As shown in Fig. S9 (see ESM), method performance for DPD and $N$ chloroglycine methods were comparable. Although the slope of the $N$-chloroglycine method was slightly closer to the ideal value (i.e., 1$)$, they were statistically equivalent $(\alpha=0.05)$. It can be concluded that the $\mathrm{N}$-chloroglycine method is capable of FAC measurement in the presence of $\mathrm{ClO}_{2}$.

Methods that are used to measure intrinsic $\mathrm{FAC}$ in $\mathrm{ClO}_{2}$ applications so far have some disadvantages. For example, in the ABTS-based method, ammonia is used as the scavenger, and monochloramine concentration is calculated by subtracting $\mathrm{ClO}_{2}$ from the total available chlorine fraction [13]. This can affect the accuracy of the ABTS method based on literature [43]. It is also needed to add $\mathrm{HgCl}_{2}$ to the sample to complex iodide and prevent the overestimation of $\mathrm{ClO}_{2}$ concentration, which is not advocated due to its high toxicity. Moreover, $\mathrm{ABTS}^{*+}$ (the colored compound subject to measurement) is not stable and reduced in the presence of hydrogen-donating antioxidants [44]. It also can react with basic carbonates and other oxidants [45]. Therefore, this radical is commonly used for the measurement of antioxidant capacity $[46,47]$.

Additionally, in comparison with glycine, ammonia has a lower reaction rate with FAC [48]. Lower reaction rate might hinder proper scavenging in the presence of compounds like amino acids that have high reaction rates with FAC [14]. This is also true for other selective scavengers like trimethoxybenzene (TMB) [49]. Moreover, monochloramine decomposes faster compared with $N$-chloroglycine [50] and is a stronger oxidant [51] reactive towards moieties such as phenol [52]. Monochloramine is also volatile [53], and for these reasons, glycine might be a more suitable scavenger.
Figure 3 represents the results for the measurement of intrinsic $\mathrm{FAC}$ in the $\mathrm{ClO}_{2}$ application. Wajon et al. [9] suggested a reaction mechanism for phenol and $\mathrm{ClO}_{2}$ with a $50 \%$ intrinsic FAC yield. This mechanism has lately been proven by Terhalle et al. [12] and Rougé et al. [13]. The results for the intrinsic FAC measurement based on the DPD method were lower than those obtained by the $N$-chloroglycine method, showing a considerably better performance for the $\mathrm{N}$ chloroglycine method. Overall, quantification of intrinsic FAC yields with DPD is very difficult (if not entirely unfeasible). Time-resolved measurement of intrinsic FAC is not possible with any method that needs subtraction of $\mathrm{ClO}_{2}$ from $\mathrm{ClO}_{2}+\mathrm{FAC}$, including DPD.

\section{Stability of reagents of the $\mathrm{N}$-chloroglycine method}

Glycine stock solution in ultra-pure water can be kept for months without any relevant change (note that biodegradation has to be ruled out), while DPD solutions can be oxidized by oxygen [54]. This phenomenon is a lot faster at higher $\mathrm{pH}$; thus, the DPD reagents always need to be kept in acidic conditions [54]. Therefore, the $\mathrm{N}$-chloroglycine method is very robust compared with DPD concerning the chemical storage of the reagents.

$\mathrm{N}$-chloroglycine, on the other hand, can undergo auto decomposition. Table 2 shows the decomposition rate of $N$ chloroglycine measured by the UV spectrometer at $254 \mathrm{~nm}$. The results confirm the lower stability of $N$-chloroglycine at pH 4 (acid-catalyzed disproportionation [55]). This fact and the run time of such a method can be regarded as a disadvantage compared with methods such as DPD that provide the results within minutes. However, instability of $N$-chloroglycine can lead to around $8 \%$ loss at $\mathrm{pH} 7$ in $8 \mathrm{~h}$ (ESM Fig. S10). On the other hand, a study on the color fading of the DPD method showed a $3 \%$ up to $29 \%$ decrease between 1 and 5 min after mixing of DPD and FAC [54]. Further information on the decomposition of $\mathrm{N}$-chloroglycine is presented in Text S2 (see ESM).
Fig. 3 Measurement of intrinsic $\mathrm{FAC}$ formation from the reaction of $\mathrm{ClO}_{2}$ with phenol using DPD and $N$-chloroglycine (IC-PCRUV) method. $10 \mu \mathrm{mol} \mathrm{L}^{-1}$ phenol samples were treated with $2-$ $40 \mu \mathrm{mol} \mathrm{L}{ }^{-1} \mathrm{ClO}_{2}$. Error bars show the standard deviation of triplicate measurements.

Measured at room temperature after $1 \mathrm{~h}$ reaction time, $\mathrm{pH}=7$, [phosphate buffer] $=5 \mathrm{mmol} \mathrm{L}-1$

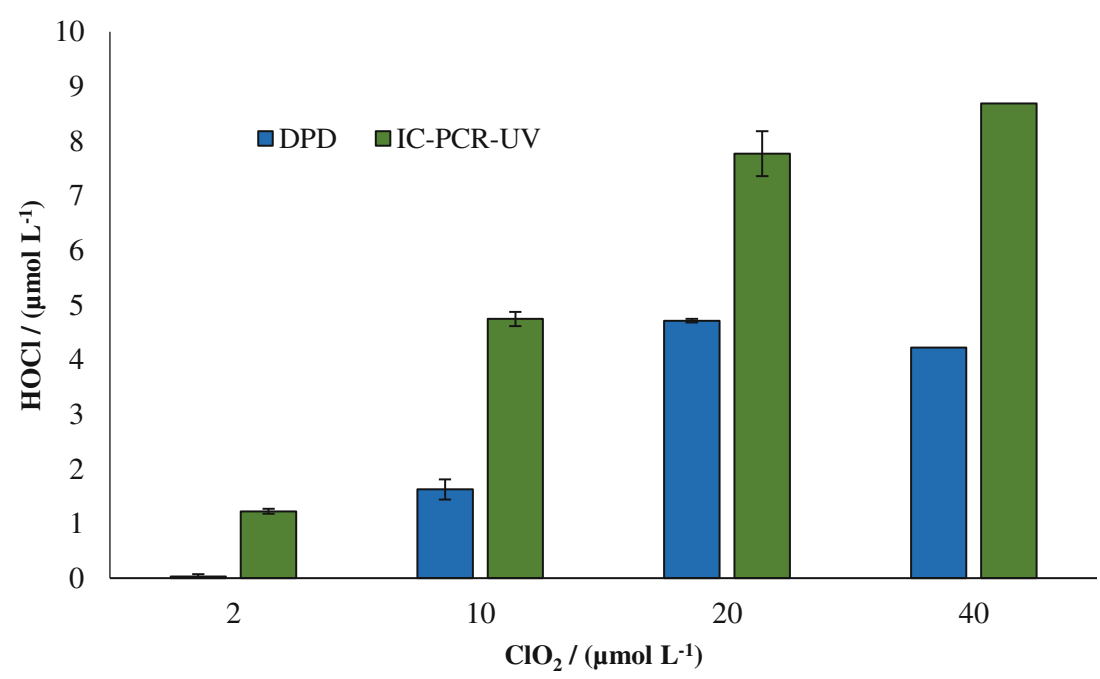


Table 2 Decomposition rate and half-life time of $N$-chloroglycine at different $\mathrm{pH}$ values measured by $\mathrm{UV}$ absorption at $254 \mathrm{~nm}$ (optical path length $=10 \mathrm{~cm}$, [phosphate buffer $]=5 \mathrm{mmol} \mathrm{L}^{-1}$ )

\begin{tabular}{llll}
\hline & $\mathrm{pH} 4$ & $\mathrm{pH} \mathrm{7}$ & $\mathrm{pH} \mathrm{10}$ \\
\hline$k\left(\mathrm{~s}^{-1}\right)$ & $8.96 \times 10^{-6}$ & $2.83 \times 10^{-6}$ & $3.53 \times 10^{-6}$ \\
$\mathrm{t}_{1 / 2}$ (hour) & 21.5 & 68.0 & 54.5 \\
\hline
\end{tabular}

\section{Conclusion}

The $N$-chloroglycine method allows determining FAC and other ions simultaneously with good sensitivity. This allows the incorporation of FAC measurements into standard IC methods to determine other anions that have to be monitored in drinking water. Measurement of FAC alongside other anions may be especially important for applications of $\mathrm{ClO}_{2}$ where chlorite and intrinsic FAC have to be monitored. Reagents of the $N$-chloroglycine method and $N$-chloroglycine itself are fairly stable. The $N$-chloroglycine method may also be a suitable reference method to corroborate FAC measurements by other methods such as the DPD method. The simplicity of the scavenging procedure alongside the stability of glycine and $N$-chloroglycine makes this method very robust and reliable. In the case of FAC measurements in the presence of other oxidants, the selectivity of $\mathrm{N}$-chloroglycine formation for FAC alongside the chromatographic separation of the compound provides an automated method with low potential of interferences.

Acknowledgments Authors thank Deutsche METROHM GmbH \& Co. KG, Filderstadt, for providing the separation column, and Mr. Markus Knepper for his valuable expert opinion and fruitful discussions.

Funding information Open Access funding provided by Projekt DEAL. The present work was supported by the German Academic Exchange Service (DAAD) with funding from the German Federal Ministry of Education and Research (BMBF) and the German Research Foundation (grant number: 426368743).

\section{Compliance with ethical standards}

Conflict of interest The authors declare that they have no conflicts of interest.

Open Access This article is licensed under a Creative Commons Attribution 4.0 International License, which permits use, sharing, adaptation, distribution and reproduction in any medium or format, as long as you give appropriate credit to the original author(s) and the source, provide a link to the Creative Commons licence, and indicate if changes were made. The images or other third party material in this article are included in the article's Creative Commons licence, unless indicated otherwise in a credit line to the material. If material is not included in the article's Creative Commons licence and your intended use is not permitted by statutory regulation or exceeds the permitted use, you will need to obtain permission directly from the copyright holder. To view a copy of this licence, visit http://creativecommons.org/licenses/by/4.0/.

\section{References}

1. McGuire MJ. Eight revolutions in the history of US drinking water disinfection. J Am Water Works Assoc. 2006;98:123-49. https:// doi.org/10.1002/j.1551-8833.2006.tb07612.x.

2. Lutze HV. Water, 6. Treatment by Oxidation Processes, in: Ullmann's Encycl. Ind. Chem., Wiley-VCH Verlag GmbH \& Co. KGaA, Weinheim, Germany; 2016. p. 1-16. https://doi.org/10. 1002/14356007.o28_o17.pub2.

3. von Gunten U. Oxidation processes in water treatment: are we on track? Environ Sci Technol. 2018;52:5062-75. https://doi.org/10. 1021/acs.est.8b00586.

4. Sedlak DL, von Gunten U. The chlorine dilemma. Science (80-. ). 2011;331:42-3. https://doi.org/10.1126/science.1196397.

5. HACH. Water analysis handbook. 7th ed. Loveland: Hach Company; 2012.

6. APHA. Standard methods for the examination of water and wastewater. 20th ed. Washington D. C: American public health association; 1999.

7. Gates DJ, Ziglio G, Ozekin K. State of the science of chlorine dioxide in drinking water: Water Research Foundation/ Fondazione AMGA; 2009.

8. Gordon G, Cooper WJ, Rice RG, Pacey GE. Methods of measuring disinfectant residuals. J Am Water Work Assoc. 1988;80:94-108. https://doi.org/10.1002/j.1551-8833.1988.tb03104.x.

9. Wajon JE, Rosenblatt DH, Burrows EP. Oxidation of phenol and hydroquinone by chlorine dioxide. Environ Sci Technol. 1982;16: 396-402. https://doi.org/10.1021/es00101a006.

10. Aguilar CAH, Narayanan J, Singh N, Thangarasu P. Kinetics and mechanism for the oxidation of anilines by $\mathrm{ClO}_{2}$ : a combined experimental and computational study. J Phys Org Chem. 2014;27:440-9. https://doi.org/10.1002/poc.3281.

11. Aguilar CAH, Narayanan J, Manoharan M, Singh N, Thangarasu P. A much-needed mechanism and reaction rate for the oxidation of phenols with $\mathrm{ClO} 2$ : a joint experimental and computational study. Aust J Chem. 2013;66:814. https://doi.org/10.1071/CH13101.

12. Terhalle J, Kaiser P, Jütte M, Buss J, Yasar S, Marks R, et al. Chlorine dioxide - pollutant transformation and formation of hypochlorous acid as a secondary oxidant. Environ Sci Technol. 2018;52:9964-71. https://doi.org/10.1021/acs.est.8b01099.

13. Rougé V, Allard S, Croué J-P, von Gunten U. In situ formation of free chlorine during $\mathrm{ClO}_{2}$ treatment: implications on the formation of disinfection byproducts. Environ Sci Technol. 2018;52:134219. https://doi.org/10.1021/acs.est.8b04415.

14. Deborde M, von Gunten U. Reactions of chlorine with inorganic and organic compounds during water treatment-kinetics and mechanisms: a critical review. Water Res. 2008;42:13-51. https:// doi.org/10.1016/j.watres.2007.07.025.

15. Hoigné J, Bader H. Kinetics of reactions of chlorine dioxide $(\mathrm{OClO})$ in water- $\mathrm{I}$. Rate constants for inorganic and organic compounds. Water Res. 1994;28:45-55. https://doi.org/10.1016/00431354(94)90118-X.

16. Armesto XL, Canle ML, Santaballa JA. $\alpha$-amino acids chlorination in aqueous media. Tetrahedron. 1993;49:275-84. https://doi.org/ 10.1016/S0040-4020(01)80525-1.

17. Armesto XL, Canle ML, García MV, Losada M, Santaballa JA. N Reactivity vs. O reactivity in aqueous chlorination. Int J Chem Kinet. 1994;26:1135-41. https://doi.org/10.1002/kin.550261108.

18. Mehrsheikh A, Bleeke M, Brosillon S, Laplanche A, Roche P. Investigation of the mechanism of chlorination of glyphosate and glycine in water. Water Res. 2006;40:3003-14. https://doi.org/10. 1016/j.watres.2006.06.027.

19. Lide DR. CRC handbook of chemistry and physics. 90th ed. Boca Raton: CRC Press; 2010. 
20. U.S. EPA Office of water. 2018 Edition of the Drinking Water Standards and Health Advisories Tables, EPA 822-F-18-001. 2018

21. WHO. Guidelines for drinking-water quality, 4 th edition - chapter 8, Guid. Drink. Water. 4th ed. 2017. p. 155-201.

22. Verordnung über die Qualität von Wasser für den menschlichen Gebrauch (Trinkwasserverordnung - TrinkwV 2001), Bundesgesetzblatt. Teil. 2016;1:459-491.

23. DIN EN ISO 10304-1. Water quality - Determination of dissolved anions by liquid chromatography of ions. 2009. https://doi.org/10. 31030/1518948.

24. U.S. Environmental Protection Agency. EPA Method 300.1, Revision 1.0: Determination of Inorganic Anions in Drinking Water by Ion Chromatography. 1993. p. 0-39. https://www.epa. gov/sites/production/files/2015-06/documents/epa-300.1.pdf.

25. Hand VC, Margerum DW. Kinetics and mechanisms of the decomposition of dichloramine in aqueous solution. Inorg Chem. 1983;22:1449-56. https://doi.org/10.1021/ic00152a007.

26. Furness-Green SM, Inskeep TR, Starke JJ, Ping L, GreenleafSchumann HR, Goyne TE. High-performance liquid chromatographic analysis of amino acid- and peptide-derived chloramines. J Chromatogr Sci. 1998;36:227-36. https://doi.org/10.1093/ chromsci/36.5.227.

27. Norm D. Water quality - determination of dissolved bromate method using ion chromatography (IC) and post column reaction (PCR) (ISO 11206:2011). 2013. https://doi.org/10.31030/1972886.

28. DIN EN ISO 7393-2. Water quality - determination of free chlorine and total chlorine - part 2: colorimetric method using N,Ndiethyl-1,4- phenylenediamine, for routine control purposes. 2017.

29. Miller JCJNC. Statistics and chemometrics for analytical chemistry. 6th ed. Pearson Education Limited; 2011. https://books.google.de/ books?id=8FtTDwAAQBAJ.

30. Gordon G, Sweetin DL, Smith K, Pacey GE. Improvements in the $\mathrm{N}, \mathrm{N}$-diethyl-p-phenylenediamine method for the determination of free and combined residual chlorine through the use of FIA. Talanta. 1991;38:145-9. https://doi.org/10.1016/0039-9140(91) 80122-G.

31. Mechelke J, Longrée P, Singer H, Hollender J. Vacuum-assisted evaporative concentration combined with LC-HRMS/MS for ultratrace-level screening of organic micropollutants in environmental water samples. Anal Bioanal Chem. 2019;411:2555-67. https://doi. org/10.1007/s00216-019-01696-3.

32. Curzon G. The oxidation of NN-dimethyl-p-phenylenediamine by oxidizing agents and by caeruloplasmin. Biochem J. 1967;103: 289-98. https://doi.org/10.1042/bj1030289.

33. Moore HE, Garmendla MJ, Cooper WJ. Kinetics of monochloramine oxidation of N, N-diethyl-p-phenylenediamine. Environ Sci Technol. 1984;18:348-53. https://doi.org/10.1021/ es00123a011.

34. Spon R. Do you really have a free chlorine residual? Opflow. 2008;34:24-7. https://doi.org/10.1002/j.1551-8701.2008.tb01993. $\mathrm{x}$.

35. Jensen JN, Johnson JD. Interferences by monochloramine and organic chloramines in free available chlorine methods. 2. N,NDiethyl-p-phenylenediamine. Environ Sci Technol. 1990;24:98590. https://doi.org/10.1021/es00077a006.

36. Sollo FW, Larson TE, McGurk FF. Colorimetric methods for bromine. Environ Sci Technol. 1971;5:240-6. https://doi.org/10.1021/ es60050a009.

37. Valentine RL. Bromochloramine oxidation of N,N-diethyl-pphenylenediamine in the presence of monochloramine. Environ Sci Technol. 1986;20:166-70. https://doi.org/10.1021/ es00144a009.

38. Körtvélyesi Z. Analytical methods for the measurement of chlorine dioxide and related oxychlorine species in aqueous solution. Miami University; 2004.
39. Dotson A, Westerhoff P. Occurrence and removal of amino acids during drinking water treatment. J Am Water Works Assoc. 2009;101:101-15. https://doi.org/10.1002/j.1551-8833.2009. tb09963.x.

40. Patai S. Amino, nitrosco and nitro compounds and their derivatives, vol. 1. Chichester: John Wiley \& Sons, Ltd.; 1982. https://doi.org/ 10.1002/9780470771662.

41. Szabó M, Baranyai Z, Somsák L, Fábián I. Decomposition of Nchloroglycine in alkaline aqueous solution: kinetics and mechanism. Chem Res Toxicol. 2015;28:1282-91. https://doi.org/10. 1021/acs.chemrestox.5b00084.

42. Coker MSA, Hu W-P, Senthilmohan ST, Kettle AJ. Pathways for the decay of organic dichloramines and liberation of antimicrobial chloramine gases. Chem Res Toxicol. 2008;21:2334-43. https:// doi.org/10.1021/tx800232v.

43. Pinkernell U, Nowack B, Gallard H, von Gunten U. Methods for the photometric determination of reactive bromine and chlorine species with ABTS. Water Res. 2000;34:4343-50. https://doi.org/ 10.1016/S0043-1354(00)00216-5.

44. Re R, Pellegrini N, Proteggente A, Pannala A, Yang M, Rice-Evans C. Antioxidant activity applying an improved ABTS radical cation decolorization assay. Free Radic Biol Med. 1999;26:1231-7. https://doi.org/10.1016/S0891-5849(98)00315-3.

45. Pinkernell U, Lüke HJ, Karst U. Selective photometric determination of peroxycarboxylic acids in the presence of hydrogen peroxide. Analyst. 1997;122:567-71. https://doi.org/10.1039/a700509a.

46. Zheng L, Zhao M, Xiao C, Zhao Q, Su G. Practical problems when using ABTS assay to assess the radical-scavenging activity of peptides: importance of controlling reaction $\mathrm{pH}$ and time. Food Chem. 2016;192:288-94. https://doi.org/10.1016/j.foodchem.2015.07. 015.

47. Dong JW, Cai L, Xing Y, Yu J, Ding ZT. Re-evaluation of ABTS-G+ assay for total antioxidant capacity of natural products. Nat Prod Commun. 2015;10:2169-72. https://doi.org/10.1177/ $1934578 \times 1501001239$.

48. How ZT, Kristiana I, Busetti F, Linge KL, Joll CA. Organic chloramines in chlorine-based disinfected water systems: a critical review. J Environ Sci. 2017;58:2-18. https://doi.org/10.1016/j.jes. 2017.05.025.

49. Lau SS, Dias RP, Martin-Culet KR, Race NA, Schammel MH, Reber KP, et al. 1,3,5-Trimethoxybenzene (TMB) as a new quencher for preserving redox-labile disinfection byproducts and for quantifying free chlorine and free bromine. Environ Sci Water Res Technol. 2018;4:926-41. https://doi.org/10.1039/C8EW00062J.

50. Lee W, Westerhoff P. Formation of organic chloramines during water disinfection - chlorination versus chloramination. Water Res. 2009;43:2233-9. https://doi.org/10.1016/j.watres.2009.02. 009.

51. Amiri F, Andrews S. Development of a size exclusion chromatography-electrochemical detection method for the analysis of total organic and inorganic chloramines. J Chromatogr Sci. 2008;46:591-5. https://doi.org/10.1093/chromsci/46.7.591.

52. Heasley VL, Fisher AM, Herman EE, Jacobsen FE, Miller EW, Ramirez AM, et al. Investigations of the reactions of monochloramine and dichloramine with selected phenols: examination of humic acid models and water contaminants. Environ Sci Technol. 2004;38:5022-9. https://doi.org/10.1021/es030644h.

53. Garcia MA, Anderson MA. The Henry's constant of monochloramine. Chemosphere. 2018;192:244-9. https://doi.org/ 10.1016/j.chemosphere.2017.10.157.

54. Cooper WJ, Roscher NM, Slifker RA. Determining free available chlorine by DPD-colorimetric, DPD-Steadifac (colorimetric), and FACTS procedures. J Am Water Works Assoc. 1982;74:362-8. https://doi.org/10.1002/j.1551-8833.1982.tb04942.x. 
55. Armesto XL, Canle ML, Losada M, Santaballa JA. An operational approach toN-Cl- $\alpha$-amino acids decomposition. Int J Chem Kinet. 1993;25:331-9. https://doi.org/10.1002/kin.550250502.

Publisher's note Springer Nature remains neutral with regard to jurisdictional claims in published maps and institutional affiliations.

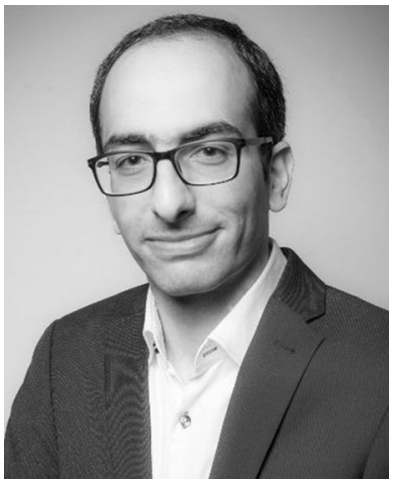

$M \circ h$ a m m a d S a j j a d Abdighahroudi is a researcher at the Technical University of Darmstadt (IWAR, Chair of Environmental Analytics and Pollutants) and a Ph.D. student at the University of Duisburg-Essen (department of Instrumental Analytical Chemistry). He holds a B.Sc. in Civil EngineeringWater and Wastewater and M.Sc. in Civil-Environmental Engineering from the Power and Water University of Technology and the University of Tehran, respectively. He is the recipient of the Metrohm Young Chemist Award 2018 as well as the DAAD scholarship Sustainable Water Management (NaWaM) 2016. His research interests lie within the oxidative water treatment and analytical chemistry. In his research, he utilizes chromatographic methods as a tool for determining mechanisms, pathways, and kinetics of oxidative processes.

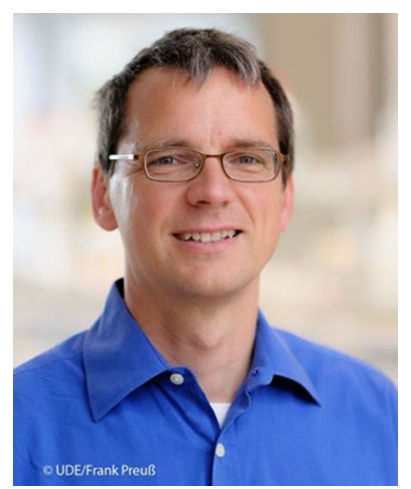

Torsten C. Schmidt is Full Professor for Instrumental Analytical Chemistry at the University of Duisburg-Essen and Scientific Director at the IWW Water Centre in Muelheim an der Ruhr. Since 2013, he has been President of the German Water Chemistry Society. In 2013, he received the Fresenius Award of the German Chemical Society. His main research interests include the development and application of analytical methods with a focus on separation techniques (GC, LC), sample preparation and compound-specific isotope analysis, process-oriented environmental chemistry, and oxidation processes in water technology.

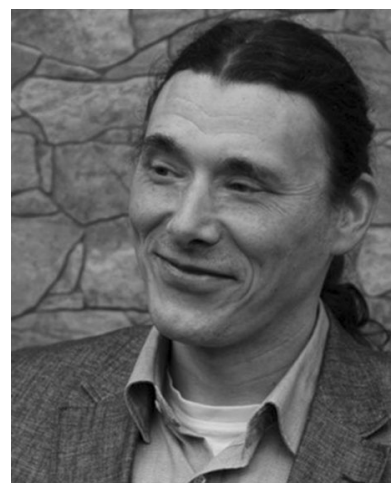

Holger V. Lutze is Professor for Environmental Analytics and Pollutants at the Technical University of Darmstadt (institute IWAR), Scientific Advisor at the IWW Water Centre, and head of the expert group Oxidative Processes of the Water Chemistry Society. His $\mathrm{PhD}$ was funded by the German Water Chemistry Society and conducted in the Instrumental Analytical Chemistry Department (University of Duisburg-Essen) where he also headed the group of oxidative Processes. In 2019, he received the award of the Water Chemistry Society for his research in the field of oxidative processes in technical and natural systems. His research areas include behavior and control of pollutants as well as fundamental reactions of natural matrix components such as organic matter and halides. His work covers fundamental processes and applications in water treatment. 